\title{
C-reactive Protein in Periodontitis and its Comparison with Body Mass Index and Smoking Behaviour
}

\author{
Sujaya Gupta, ${ }^{1}$ Shaili Pradhan, ${ }^{2}$ Sushil KC, ${ }^{3}$ Sonika Shakya, ${ }^{4}$ Mohana Giri ${ }^{2}$ \\ 'Department of Periodontics, Kantipur Dental College, Basundhara, Kathmandu, Nepal, ${ }^{2}$ Department of Dental Surgery, \\ NAMS, Bir Hospital, Kathmandu, Nepal, ${ }^{3}$ Department of Dental Surgery, Shree Birendra Army Hospital, Chhauni, \\ Kathmandu, Nepal, ${ }^{4}$ Department of Periodontics, KIST Medical College, Kathmandu, Nepal.
}

\begin{abstract}
Introduction: Chronic periodontitis is an infectious disease resulting in inflammation within the supporting tissues of the teeth, progressive attachment loss, and bone loss. In addition to declining oral health, there is always low grade infection present in periodontitis. Studies show increased levels of systemic biomarkers in periodontal disease such as CRP, which is considered a key-marker of CVD. Research has also shown positive association between BMI and smoking with periodontitis and CRP. The objective of the study was to assess the levels of CRP in patients with and without periodontitis and their relation with BMI and smoking behaviour.
\end{abstract}

Methods: Patients visiting the Dental department of Bir Hospital were invited to participate in the study. Total 31 subjects in each group: Case (periodontitis) and Control (without periodontitis) were selected using convenience sampling technique. All subjects underwent periodontal examination by a single examiner. Serum CRP samples were taken before periodontal treatment. Data analysis was done by SPSS 17 software program.

Results: Increase in mean CRP levels in periodontitis $(5.8595 \mathrm{mg} / \mathrm{L})$ with high statistical significance $(\mathrm{P}=0.000)$ in comparison to subjects without periodontitis $(1.1214 \mathrm{mg} / \mathrm{L})$ was observed. BMI showed positive association with periodontitis $(\mathrm{P}=0.046)$ but not with CRP $(0.213)$. Smoking behaviour showed no significant relation with either $\mathrm{CRP}(\mathrm{P}=0.344)$ or periodontitis $(\mathrm{P}=0.541)$.

Conclusions: We found highly significant association between periodontitis and CRP levels but not always with BMI and smoking. CRP, which is an established marker for CVD was significantly increased in periodontal infections. Hence, a close interaction among Physician, Periodontist and Patient to prevent adverse health situations is recommended.

Keywords: body mass index; cardiovascular disease; c-reactive protein; periodontitis; smoking; systemic inflammation.

\section{INTRODUCTION}

Periodontitis is a chronic infection of gingiva characterized by loss of attachment between tooth and bone and bone loss. ${ }^{1}$ Although periodontitis is chronic in nature, acute-phase elements are also part of immune-response in periodontitis and confirm presence of systemic inflammation. ${ }^{2,3}$ C-reactive protein (CRP)

Correspondence: Dr. Sujaya Gupta, Kantipur Dental College, Basundhara, Kathmandu, Nepal. Email: sujayaagupta@gmail.com, Phone: +977-9803588959. 
is regarded as biomarker of systemic inflammation and elevated plasma CRP levels as risk predictor for cardiovascular disease (CVD). ${ }^{4}$

Smoking is another variable strongly related to both CVD as well as chronic periodontitis (CP). ${ }^{5,6} \mathrm{CP}$ and body mass index (BMI) are jointly associated with increase in CRP levels in otherwise healthy adults. ${ }^{7}$ When compared with unaffected control populations, patients with periodontitis have increased serum levels of CRP. ${ }^{8}$ Often, smoking and $\mathrm{BMI}$ are seen strongly associated with both periodontitis and CRP levels. ${ }^{5}$ Severe periodontitis and increased BMI jointly cause increase in CRP in otherwise healthy adults. ${ }^{7}$

We aim to find out the associations of periodontitis cases with elevated CRP levels and their comparison with $\mathrm{BMI}$ and smoking.

\section{METHODS}

A hospital based cross-sectional observational study was carried out in the Department of Dental Surgery, Periodontology and Oral Implantology (Perio) Unit, National Academy of Medical Sciences (NAMS), Bir Hospital, Kathmandu from September 2013 to March 2015.

Ethical Approval was taken from IRB-NAMS. The written consents were taken from the participants. Confidentiality was maintained to the utmost. No names, documents or results are disclosed/circulated anywhere other than hospital doctors or research guide. The names of the participants do not appear in the final report.

The inclusion criteria included: individuals of $\geq 25$ years of age with presence of at least one tooth (anterior/ posterior) having periodontal probing depth (PPD) $\geq 5$ $7 \mathrm{~mm}$ in each quadrant; presence of $>16$ teeth in mouth excluding third molars. Whereas exclusion criteria comprised of: presence of known systemic diseases/ infections that may influence the course of CP; history of antibiotics, NSAIDs or mouth rinses within last three months; periodontal treatment three months prior to study; pregnant or intention of becoming pregnant at the examination time; lactating females; individuals taking oral contraceptive pills; patients requiring emergency treatment; regular use of medication; history of trauma or tooth extraction in the past month; refusal of informed consent.

Minimum of 31 subjects in each group i.e., 31 cases (with CP) and 31 controls (without CP) in altogether 62 patients were enrolled in the study.

The sample size was calculated by using data from the study of Paraskevas et al. (2008) ${ }^{4}$ in formula:

$$
\mathrm{n}=\frac{\mathrm{Z}_{\alpha}^{2} \mathrm{~S}^{2}}{\mathrm{~d}^{2}}=30.884
$$

Convenience sampling was taken. The volunteers were screened in Perio Unit for presence or absence of periodontitis. Initial data was obtained by history taking and clinical examination. All subjects underwent periodontal examination by a single examiner. The instruments used were: mouth mirror and University of North Carolina (UNC)-15 periodontal probe. Peripheral blood samples for serum CRP test were taken before periodontal treatment. The findings were filled in the proforma developed for this study and data was entered in Microsoft Excel. The statistical analyses were performed using Statistical Package for Social Sciences (SPSS) software program version 17.0.Chicago: SPSS Inc.

The difference in CRP levels among study groups and its association with BMl, smoking status (current, former versus non-smoker) and number of cigarettes per day was evaluated. The significance of the various parameters in both groups was assessed by Independent t-test. P-value $<0.5$ was considered significant. Potential confounders considered were: age, ethnicity, gender, dietary habits, academic background (primary, secondary, higher-secondary etc), and occupation.

\section{RESULTS}

A total of 62 individuals, both males and females, $\geq 25$ years age were included in the present study.

\begin{tabular}{|c|c|c|c|c|c|}
\hline \multicolumn{6}{|c|}{$\begin{array}{l}\text { Table 1. Relationship of Periodontitis with Serum } \\
\text { CRP levels. }\end{array}$} \\
\hline \multirow{3}{*}{ CRP } & & $\begin{array}{c}\text { Sample } \\
\text { (n) }\end{array}$ & $\begin{array}{l}\text { Mean } \\
(\mathrm{mg} / \mathrm{L})\end{array}$ & $\begin{array}{l}\text { Standard } \\
\text { deviation }\end{array}$ & $\begin{array}{c}\text { Standard } \\
\text { error } \\
\text { mean }\end{array}$ \\
\hline & Case & 31 & 5.8595 & 4.56581 & 0.82004 \\
\hline & Control & 31 & 1.1214 & 0.89266 & 0.16033 \\
\hline
\end{tabular}

$P$ value $=0.000$, Independent t-test (2-tailed) at confidence interval 95\% 
Gupta et al. C-reactive Protein in Periodontitis and its Comparison with Body Mass Index and Smoking Behaviour

\begin{tabular}{|c|c|c|c|c|}
\hline Parameters & Case (31) & Control (31) & Total (62) & $\mathrm{P}$ value \\
\hline CRP $\mathrm{mg} / \mathrm{L}$ & n (\%) & $\mathrm{n}(\%)$ & $\mathrm{n}(\%)$ & \\
\hline $0-3$ & $7(22.6)$ & $30(96.8)$ & $37(59.7)$ & 0.000 \\
\hline$>3$ & $24(77.4)$ & $1(3.2)$ & $25(40.3)$ & \\
\hline \multicolumn{5}{|c|}{ Smoking behavior } \\
\hline Current smoker & $8(25.8)$ & $7(22.6)$ & $15(24.2)$ & \\
\hline Former smoker & $8(25.8)$ & $5(16.1)$ & $13(21)$ & 0.541 \\
\hline Nonsmoker & $15(48.4)$ & $19(61.3)$ & $34(54.8)$ & \\
\hline \multicolumn{5}{|c|}{ Cigarette per day } \\
\hline$<5$ & $16(51.6)$ & $24(77.4)$ & $40(64.5)$ & \\
\hline $5-<10$ & $8(25.8)$ & $2(6.5)$ & $10(16.1)$ & \\
\hline $10-<15$ & $5(16.1)$ & $2(6.5)$ & $7(11.3)$ & 0.066 \\
\hline $15-<20$ & - & $2(6.5)$ & $2(3.2)$ & \\
\hline$>20$ & $2(6.5)$ & $1(3.2)$ & $3(4.8)$ & \\
\hline \multicolumn{5}{|l|}{$\mathrm{BMI}$} \\
\hline Underweight & - & - & - & \\
\hline Normal & $19(61.3)$ & 26 (83.9) & $45(72.6)$ & 0.046 \\
\hline Overweight & $12(38.7)$ & $5(16.1)$ & $17(27.4)$ & \\
\hline Obese & - & - & - & \\
\hline \multicolumn{5}{|l|}{ Age (years) } \\
\hline $25-35$ & $10(32.3)$ & $20(64.5)$ & $30(48.4)$ & \\
\hline $36-50$ & $14(45.2)$ & $8(25.8)$ & $22(35.5)$ & 0.037 \\
\hline$>50$ & $7(22.6)$ & $3(9.7)$ & $10(16.1)$ & \\
\hline \multicolumn{5}{|l|}{ Dietary habits } \\
\hline Mixed & $22(71)$ & $22(71)$ & $44(71)$ & 1.000 \\
\hline Vegetarian & $9(29)$ & $9(29)$ & $18(29)$ & \\
\hline Sex & & & & \\
\hline Female & $13(54.2)$ & $11(45.8)$ & $24(38.7)$ & 0.602 \\
\hline Male & $18(47.4)$ & $20(52.6)$ & 38 (61.3) & \\
\hline Ethnicity & & & & \\
\hline Aryan & $20(64.5)$ & 26 (83.9) & $46(74.2)$ & \\
\hline Mongoloid & $2(6.5)$ & - & $2(3.2)$ & 0.140 \\
\hline Mixed & 9 (29) & $5(16.1)$ & $14(22.6)$ & \\
\hline Occupation & & & & \\
\hline Business & $3(9.7)$ & $6(19.4)$ & $9(14.5)$ & \\
\hline Farming & $1(3.2)$ & $1(3.2)$ & $2(3.2)$ & \\
\hline Manual Labourer & $3(9.7)$ & $4(12.9)$ & $7(11.3)$ & 0.7 \\
\hline Service & $15(48.4)$ & $10(32.3)$ & $25(40.3)$ & \\
\hline Unemployed & $9(29.0)$ & $10(32.3)$ & $19(30.6)$ & \\
\hline Educational le & & & & \\
\hline Primary and below & $4(12.9)$ & $1(3.2)$ & $5(8.1)$ & \\
\hline Secondary & $3(9.7)$ & $6(19.4)$ & $9(14.5)$ & 0.347 \\
\hline Higher secondary & $4(12.9)$ & $6(19.4)$ & $10(16.1)$ & \\
\hline Bachelors and above & $20(64.5)$ & $18(58.1)$ & $38(61.3)$ & \\
\hline
\end{tabular}

Coincidently, both cases and control groups in present study had equal distribution of Mixed (22, 71\%) and Vegetarian (9, $29 \%$ ) dietary habits (Table 2 ). 
Gupta et al. C-reactive Protein in Periodontitis and its Comparison with Body Mass Index and Smoking Behaviour

\begin{tabular}{|c|c|c|c|c|}
\hline \multirow[t]{2}{*}{ Parameters } & CRP 0-3mg/L 37 (59.7\%) & CRP > 3mg/L 25 (40.3\%) & Total (62) & $P$ value \\
\hline & n (\%) & n (\%) & n (\%) & \\
\hline \multicolumn{5}{|l|}{ Case/Control } \\
\hline Case & $7(22.6)$ & $24(77.4)$ & $31(50)$ & 0.000 \\
\hline Control & $30(96.8)$ & $1(3.2)$ & $31(50)$ & \\
\hline \multicolumn{5}{|l|}{ Smoking behavior } \\
\hline Current smoker & $8(53.3)$ & $7(46.7)$ & $15(24.2)$ & \\
\hline Former smoker & $6(46.2)$ & $7(53.8)$ & $13(21)$ & 0.344 \\
\hline Nonsmoker & $23(67.6)$ & $11(32.4)$ & $34(54.8)$ & \\
\hline \multicolumn{5}{|l|}{ Cigarette per day } \\
\hline$<5$ & $28(70)$ & $12(30)$ & $40(64.5)$ & \\
\hline $5-<10$ & $4(40)$ & $6(60)$ & $10(16.1)$ & \\
\hline $10-<15$ & $2(28.6)$ & $5(71.4)$ & $7(11.3)$ & 0.078 \\
\hline $15-<20$ & $2(100.0)$ & - & $2(3.2)$ & \\
\hline$>20$ & $1(33.3)$ & $2(66.7)$ & $3(4.8)$ & \\
\hline \multicolumn{5}{|l|}{ BMI } \\
\hline Underweight & - & - & - & \\
\hline Normal & $29(64.4)$ & $16(35.6)$ & $45(72.6)$ & 0.213 \\
\hline Overweight & $8(47.1)$ & $9(52.9)$ & $17(27.4)$ & \\
\hline Obese & - & - & - & \\
\hline \multicolumn{5}{|l|}{ Age (years) } \\
\hline $25-35$ & $20(66.7)$ & $10(33.3)$ & $30(48.4)$ & \\
\hline $36-50$ & $12(54.5)$ & $10(45.5)$ & $22(35.5)$ & 0.538 \\
\hline$>50$ & $5(50)$ & $5(50)$ & $10(16.1)$ & \\
\hline \multicolumn{5}{|l|}{ Dietary habits } \\
\hline Mixed & $27(61.4)$ & $17(38.6)$ & $44(71)$ & \\
\hline Vegetarian & $10(55.6)$ & $8(44.4)$ & $18(29)$ & 0.672 \\
\hline \multicolumn{5}{|l|}{ Sex } \\
\hline Female & $15(62.5)$ & 9 (37.5) & $24(38.7)$ & 0.719 \\
\hline Male & 22 (57.9) & $16(42.1)$ & $38(61.3)$ & \\
\hline \multicolumn{5}{|l|}{ Ethnicity } \\
\hline Aryan & $28(60.9)$ & $18(39.1)$ & $46(74.2)$ & \\
\hline Mongoloid & $1(50)$ & $1(50)$ & $2(3.2)$ & 0.931 \\
\hline Mixed & $8(57.1)$ & $6(42.9)$ & $14(22.6)$ & \\
\hline \multicolumn{5}{|l|}{ Occupation } \\
\hline Business & $6(66.7)$ & 3 (33.3) & $9(14.5)$ & \\
\hline Farming & $1(50)$ & $1(50)$ & $2(3.2)$ & 0.849 \\
\hline Manual Labourer & $5(71.4)$ & $2(28.6)$ & $7(11.3)$ & \\
\hline Service & $13(52)$ & $12(48)$ & $25(40.3)$ & \\
\hline Unemployed & $12(63.2)$ & $7(36.8)$ & $19(30.6)$ & \\
\hline \multicolumn{5}{|l|}{ Educational level } \\
\hline Primary and below & $2(40)$ & $3(60)$ & $5(8.1)$ & \\
\hline Secondary & 8 (88.9) & $1(11.1)$ & $9(14.5)$ & 0.230 \\
\hline Higher secondary & $6(60)$ & $4(40)$ & $10(16.1)$ & \\
\hline Bachelors and above & $21(55.3)$ & $17(44.7)$ & $38(61.3)$ & \\
\hline
\end{tabular}


Out of 31 individuals, 26 subjects without periodontitis had normal BMI ( $\mathrm{P}=0.046$; Table 2). No significant association of CRP with age, gender, BMI, dietary habits, educational level or occupation reported. However, a statistically significant relationship was observed with Ethnicity $(P=0.026)$ with "Aryans" being more in the Control group (Table 3).

\section{DISCUSSION}

Periodontitis, a chronic inflammatory disorder caused by bacterial plaque, is one of the most common but often undiagnosed diseases in human. It is characterized by the destruction of tooth-supporting tissues. Periodontal disease is the most important cause of tooth loss in individuals $>45$ years and along with caries, is the most frequent oral health problem worldwide. ${ }^{9}$ In the current study, individuals of 25 years and above were invited to participate as CP commonly affects middleaged adults and elderly. ${ }^{10}$

Several biochemical markers of systemic inflammation have been identified in periodontitis. The quest for markers like CRP, that are indicative of periodontal disease, is a long one and the correlation of marker levels with systemic disease multiplies the importance of such markers. ${ }^{11}$ CRP has recently gained special attention as a risk factor for cardiac and cerebrovascular events. ${ }^{4}$

Many investigators have implicated that chronic infections as well as inflammatory mechanisms play a major role in atherogenesis and CVD and consider $\mathrm{CP}$ as a risk factor of CVD. ${ }^{12,13} \mathrm{~A}$ number of studies have examined the relationship between CRP and periodontitis. $^{8,14}$ Recent evidence indicates that patients with periodontitis have increased serum levels of CRP when compared with unaffected control populations..$^{8,12,15,16}$

The present study was undertaken to further investigate and substantiate the relationship of elevated levels of high-sensitivity-CRP (hs-CRP) with CP and to assess the cardiovascular risk in patients with $\mathrm{CP}$ by examining their serum CRP levels and comparing them with those of Controls. It is one of the first epidemiological studies done in hospital population in Nepal and very few publication of such study exists till date.

The normal range of CRP levels in healthy individuals is noted to be $2-3 \mathrm{mg} / \mathrm{L}$. CRP $>3 \mathrm{mg} / \mathrm{L}$ is considered indicative of high risk for developing atherosclerotic CVD. Whereas according to American Heart Association (AHA), ${ }^{17}$ cardiac risk and CRP levels can be correlated as $<1 \mathrm{mg} / \mathrm{L}=$ low risk, $1-3 \mathrm{mg} / \mathrm{L}=$ moderate risk, $>3$ $\mathrm{mg} / \mathrm{L}=$ high risk.

In this clinical study, comparison among the mean CRP levels in Case (CP) and Control (without CP) showed an increase in mean CRP levels in CP with a high statistical significance $(P=0.000)$ in comparison to subjects without CP (Table 1). This was in accordance with the findings of Slade et al., ${ }^{7}$ Loos et al., ${ }^{2}$ Gani et al. ${ }^{8}$ and Schenkein et al. ${ }^{11}$ Similar to the studies, where CRP levels were significantly lower in individuals without $\mathrm{CP}$ than with $\mathrm{CP}$, in current study the control group demonstrated near normal CRP level (Table 1) indicating little or no risk for CVD. $8,12,18$ However, Ide et al. ${ }^{19}$ reported no significant changes in CRP levels, and improvement in periodontal health also did not influence the levels of vascular markers. It could be because of their small sample size and short follow-up with blood samples measured at 0, 15, 30, 60 and 120 minutes post scaling and root planing.

Experimental conformation of the present study further emphasize that another widely prevalent and preventable contributor to the burden of CVD (in form of periodontitis) would be added to the options available to the clinicians and public health practitioners for the control of the epidemic of CVD. ${ }^{20}$

Another etiological factor that has been strongly associated with periodontitis as well as CVD is tobacco smoking. Smoking behaviour was categorized as Current smokers, Former smokers and Nonsmokers. ${ }^{21}$ Current smokers have smoked $\geq 100$ cigarettes in their lifetime and currently smoke, Former smokers have smoked $\geq 100$ cigarettes in their lifetime and do not currently smoke and Nonsmokers have not smoked $\geq 100$ cigarettes in their lifetime and do not currently smoke.

Comparison of CRP with smoking behaviour showed no significant relation $(P=0.541$; Table 3$)$ in contrast to Shahabi et al. ${ }^{6}$ study, which demonstrates significant relationship of CRP levels and smoking $(P=0.001)$. The difference could be attributed to a separate grouping of "former smokers." Also majority of subjects were Nonsmokers (Table 2). This study is also in disagreement with $\mathrm{Vu}$ et al. ${ }^{22}$ who reported an average risk with hsCRP levels ( $>1-<3 \mathrm{mg} / \mathrm{L}$ ) in smokers. The difference in results could be attributed to short term follow-up (one month) of their study. Thus hs-CRP should be measured at more points of time. The Nonsmokers percentage was more than twice in CRP group of $\leq 3 \mathrm{mg} / \mathrm{L}$ indicating decreased cardiac risk. This variation about smoking and periodontal disease could be attributed to cultural pressures influence self-reporting of cigarette consumption ${ }^{5}$ thus affecting the accuracy of smoking behaviour and number of cigarettes per day. In a society like ours, where despite the increased prevalence of smokers, cigarette smoking is considered a taboo or adverse habit, individuals might not have given true smoking status, hence accounting for more number 
of "nonsmokers" in the present study. However, our results did show that there were more "nonsmokers" $(19,61.3 \%)$ in control group.

$\mathrm{CP}$ and $\mathrm{BMI}$ are jointly associated with increase in CRP levels in otherwise healthy adults. ${ }^{7}$ Numerous studies on BMI and persistent subclinical inflammation and risk of associated death have been published. BMI can be calculated using standard formula (weight in kilograms divided by the square of height in meters). ${ }^{7}$

Epidemiological studies have shown positive association between BMI and Periodontitis and BMI and CRP 23,24 and the primary mechanism is thought to be production of TNF- $\alpha$ by adipocytes, which in turn, stimulates CRP synthesis in liver. ${ }^{23}$ Recently, Pitchika et al. ${ }^{14}$ reported significant positive association between hs-CRP with gingivitis, smoking and overweight/obesity. Present study also showed statistically significant $(P=0.046)$ relation of periodontitis and BMI (Table 2). However, among all subjects, there were no underweight or obese in present study, thus explaining lack of relation of CRP with BMI (Table 3). BMI categories used in this study was the World Health Organization (Geneva, Switzerland) and the National Heart, Lung, and Blood Institute (Bethesda, Maryland, USA) developed standard categories of $\mathrm{BMI}{ }^{25}$ : $\mathrm{BMI}$ of $<18.5=$ underweight, BMI between 18.5-24.9 = normal weight, BMI between 25.0-29.9 = overweight, and BMI of $\geq 30$ = obesity.

In periodontitis and obesity, there is 2-stage hepatic activation of the CRP response, one that induces mild CRP elevation (i.e. a 1.8-fold increase in individuals with $\mathrm{BMI}<30$ ) and a second dynamic response that results in a 3-to-1000-fold increase in CRP, above the $10 \mathrm{mg} / \mathrm{L}$ cutoff point. This is consistent with the fact that periodontal disease progression is episodic with periods of acute exacerbation. Thus, periodontal diseases serving as both chronic and acute stimulus of hepatic CRP.

The results agreed with previous 39-year long follow-up study (Vu et al.) ${ }^{22}$ which showed higher levels of CRP in overweight and obese individuals. However, it is in contrast with Awad et al. ${ }^{24}$ study which did not show significant association of periodontitis with BMI.

Increasing importance has been placed on the social determinants like academic background, occupation, socioeconomic status (SES) and race/ethnicity on health and disease. There was no association observed of CRP with BMI, age, gender, similar to Steele et al. ${ }^{26}$ but it was significant with ethnicity $(P=0.026)$ with more "Aryans" in Control group. It could be because majority of sample size $(46,74.19 \%$ ) were Aryans (Table 3).

The present study also showed statistically significant
$(P=0.037)$ relationship of increasing age with periodontitis (Table 2). This is in agreement with Bourgeois et al. ${ }^{27}$ They reported that prevalence and severity of periodontitis increased with age. Similarly, Albandar et al. ${ }^{28}$ demonstrated that age as well as gender may influence periodontal health and individuals between 40-50 years old had worse periodontal health. Accordingly, Holtfreter et al. ${ }^{29}$ demonstrated that $76.9 \%$ of adults (35-45years) had PPD $\geq 4 \mathrm{~mm}$. But no such correlation was seen with varying CRP levels and age (Table 3 ). In contrast, Bonfim et al. ${ }^{30}$ reported significant association of periodontitis with years of schooling, racial background and SES. Periodontal health was worse $(\geq 6 \mathrm{~mm})$ in adult females of black/ mixed race with $\leq 8$ years of schooling and least income thus concluding that socioeconomic and demographic characteristics were related with $\mathrm{CP}$.

One reason for demographics having no significant relationship with $\mathrm{CP}$ could be because it was self-reported criteria and patient may not always have been truthful with the examiner. Also the criteria for occupation should have been more specific. Government, public/private workers, even banker as well as lawyers were placed under single variable "Service." Students, homemakers, and unemployed were categorized together. And, for business and manual-labour, what kind of business or manual labour not specified? Drivers were placed under manual-labour but they could have been in government service as well. And even helpers in the government job considered themselves to be included under Service. Clearly defined criteria would have ascertained the relationship more accurately. About "Education", majority of our sample were graduate and above (Table 2). One reason could be because of lack of oral health awareness in less educated individuals of Nepal.

Unlike studies in Western population, where nonhispanic Blacks seem to have more prevalence and severity of $\mathrm{CP}$, no such correlation could be observed in current study. Proper evaluation could not be performed as most subjects were Aryan (46, 74.19\%) (Table 2).

About association with gender, numerous authors have stated that gender can play an important role in the health or disease due to varying health behaviours. Majority of studies show women have better oral hygiene than men and visit the dentist more often. However, few research report adult females having worse periodontal status. ${ }^{30}$ The authors argued that the disparity could be because theirs' was a household study and females continue to be home more often. In contrast, no significant difference observed with gender in present study. Determining gender-specific differences in CRP may alter how CRP levels are interpreted and used to determine risk. Lakoski et al. ${ }^{17}$ reported that overall women had higher median CRP compared 
with men $(2.56$ vs $1.43 \mathrm{mg} / \mathrm{L})$ despite accounting for $\mathrm{BMI}$ and other common confounding variables. This gender difference was maintained across all ethnic subgroups. In contrast, Holtfreter et al. ${ }^{29}$ demonstrated the prevalence of PPD $\geq 4 \mathrm{~mm}$ were higher among men. These results suggest that evaluation of gender-specific CRP to determine cardiovascular risk.

Periodontitis is a mixed infection of supporting structures of the teeth, and thus leads to a port of entry for bacteria. The total volume of inflamed periodontal tissue may also play a vital role. Subsequently, the bacteremia as well as cytokines from the periodontal lesion will stimulate the hepatocytes and leukocytes to produce CRP. In the present study also, there was a tendency for higher CRP levels in CP cases compared to controls. While this difference between control and periodontitis case group is highly significant, the elevated CRP levels in both the groups are above the margin of risk that cannot be ignored. CRP is a very early and sensitive marker of chronic inflammation. In a systemic environment that does not cloud its levels, its value can yield very useful information for the diagnosis of the underlying inflammatory condition.

AHA, Centers for Disease Control and Prevention guidelines support the measurement of CRP in individuals with periodontal diseases for early diagnosis of risk for heart disease. ${ }^{17}$

The limitation of the study was that it was only a comparative cross sectional (observational) study for short period of time with small sample-size. CRP levels post periodontal treatment, were not compared. It is also important to highlight that etiology of both periodontitis and CVD is multifactorial and hs-CRP as marker of systemic inflammation is only one of the many biochemical markers which have not been included in the present study.

\section{CONCLUSIONS}

There was highly significant association between periodontitis and CRP levels but not always with BMI and smoking. The association of a persistent infection such as CP with hs-CRP levels is highly significant which potentially has an impact on inflammation associated atherosclerotic processes, like CVD. The knowledge that elevated CRP levels due to periodontitis has potential utility as risk marker for CVD should be emphasized.

Hence, multi-centric, large population based interventional studies with CRP levels measured at baseline and one, three and six months after periodontal therapy is recommended. Measurements of other concurrent systemic inflammatory parameters alongside would be useful. A close interaction of general physician and periodontist to prevent adverse health situations is strongly needed.

\section{ACKNOWLEDGEMENTS}

We acknowledge the support and guidance from Dr. Manoj Humagain, Dr. Ranjita Shrestha, Dr. Anjana Maharjan, Mr. Sushan Shrestha, Mr. Murali Manohar Gupta and Ms. Sarala Maharjan.

\section{Conflict of Interest: None.}

\section{REFERENCES}

1. Joshipura KJ, Wand HC, Merchant AT, Rimm EB. Periodontal disease and biomarkers related to cardiovascular disease. J Dent Res. 2004 Feb;83(2):151-5. [PubMed | Full Text | DOI]

2. Loos BG. Systemic markers of inflammation in periodontitis. J Periodontol. 2005 Nov;76(11 Suppl):2106-15. [PubMed | Full Text | DOI]

3. Ebersole JL, Cappelli D. Acute-phase reactants in infections and inflammatory diseases. Periodontol 2000. 2000 Jun;23:19-49. [PubMed | Full Text | DOI]

4. Paraskevas S, Huizinga JD, Loos BG. A systematic review and meta-analyses on C-reactive protein in relation to periodontitis. J Clin Periodontol. 2008 Apr;35(4):277-90. [PubMed | Full Text | DOI]
5. Scott DA, Palmer RM, Stapleton JA. Validation of smoking status in clinical research into inflammatory periodontal disease. J Clin Periodontol. 2001 Aug;28(8):715-22. [PubMed | Full Text | DOI]

6. Shahabi P, Cuisset T, Stathopoulou MG, et al. Genetic determined low response to thienopyridines is associated with higher systemic inflammation in smokers. Pharmacogenomics. 2015;16(5):459-69. [PubMed | Full Text | DOI]

7. Slade GD, Ghezzi EM, Heiss G, et al. Relationship between periodontal disease and C-reactive protein among adults in the Atherosclerosis Risk in Communities study. Arch Intern Med. 2003 May 26;163(10):1172-9. [PubMed | Full Text | DOI] 
8. Gani DK, Lakshmi D, Krishnan R, et al. Evaluation of C-reactive protein and interleukin-6 in the peripheral blood of patients with chronic periodontitis. J Indian Soc Periodontol. 2009 May;13(2):69-74. [PubMed | Full Text | DOI]

9. Armitage GC. Development of a classification system for periodontal diseases and conditions. Ann Periodontol. 1999 Dec;4(1):1-6. [PubMed | Full Text | DOI]

10. Uriza CL, Arregoces FE, Porras JV, et al. Ultra-Sensitive C-Reactive Protein (US-CRP) in Patients With Periodontal Disease and Risk of Acute Myocardial Infarction. Cardiol Res. 2011 Feb;2(1):27-35. [PubMed | Full Text | DOI]

11. Schenkein HA, Loos BG. Inflammatory mechanisms linking periodontal diseases to cardiovascular diseases. J Clin Periodontol. 2013 Apr;40 Suppl 14:S51-69. [PubMed | Full Text | DOI]

12. Kumar KR, Ranganath V, Naik R, et al. Assessment of high-sensitivity $\mathrm{C}$-reactive protein and lipid levels in healthy adults and patients with coronary artery disease, with and without periodontitis--a cross-sectional study. J Periodontal Res. 2014 Dec;49(6):836-44. [PubMed | Full Text | DOI]

13. Bokhari SA, Khan AA, Butt AK, et al. Periodontitis in coronary heart disease patients: strong association between bleeding on probing and systemic biomarkers. J Clin Periodontol. 2014 Nov;41(11):1048-54. [PubMed | Full Text | DOI]

14. Pitchika V, Thiering E, Metz I, et al. Gingivitis and lifestyle influences on high-sensitivity C-reactive protein and interleukin 6 in adolescents. J Clin Periodontol. 2017 Apr;44(4):372-81. [PubMed | Full Text | DOI]

15. Teeuw WJ, Slot DE, Susanto H, et al. Treatment of periodontitis improves the atherosclerotic profile: a systematic review and meta-analysis. J Clin Periodontol. 2014 Jan;41(1):70-9. [PubMed | Full Text | DOI]

16. Caúla AL, Lira-Junior R, Tinoco EM, et al. The effect of periodontal therapy on cardiovascular risk markers: a 6-month randomized clinical trial. J Clin Periodontol. 2014 Sep;41(9):875-82. [PubMed | Full Text | DOI]

17. Lakoski SG, Cushman M, Criqui M, et al. Gender and C-reactive protein: data from the Multiethnic Study of Atherosclerosis (MESA) cohort. Am Heart J. 2006 Sep;152(3):593-8. [PubMed | Full Text | DOI]

18. Goyal L, Bey A, Gupta ND, et al. Comparative evaluation of serum C-reactive protein levels in chronic and aggressive periodontitis patients and association with periodontal disease severity. Contemp Clin Dent. 2014 Oct;5(4):484-8. [PubMed | Full Text | DOI]
19. Ide M, Jagdev D, Coward PY, et al. The short-term effects of treatment of chronic periodontitis on circulating levels of endotoxin, C-reactive protein, tumor necrosis factor-alpha, and interleukin-6. J Periodontol. 2004 Mar;75(3):420-8. [PubMed | Full Text | DOI]

20. Bansal T, Pandey A, D D, et al. C-Reactive Protein (CRP) and its Association with Periodontal Disease: A Brief Review. J Clin Diagn Res. 2014 Jul;8(7):ZE21-4. [PubMed | Full Text | DOI]

21. Newman MG, Takei H, Klokkevold PR, Carranza FA, editors. Carranza's Clinical Periodontology - A South Asia Edition. 11th ed. New Delhi, India: Saunders, Elsevier; 2011. [PubMed | Full Text | DOI]

22. $\mathrm{Vu} \mathrm{TH}, \mathrm{Liu} \mathrm{K}$, Lloyd-Jones DM, et al. Favorable Levels of All Major Cardiovascular Risk Factors at Younger Ages and High-Sensitivity C-Reactive Protein 39 Years Later -The Chicago Healthy Aging Study. Prev Med Rep. 2015;2:235-40. [PubMed | Full Text | DOI]

23. Hak AE, Stehouwer CD, Bots ML, et al. Associations of C-reactive protein with measures of obesity, insulin resistance, and subclinical atherosclerosis in healthy, middle-aged women. Arterioscler ThrombVasc Biol. 1999 Aug;19(8):1986-91. [PubMed | Full Text | DOI]

24. Awad M, Rahman B, Hasan H, et al. The Relationship between Body Mass Index and Periodontitis in Arab Patients with Type 2 Diabetes Mellitus. Oman Med J. 2015 Jan;30(1):36-41. [PubMed | Full Text | DOI]

25. Flegal KM, Kit BK, Graubard BI. Body mass index categories in observational studies of weight and risk of death. Am J Epidemiol. 2014 Aug;180(3):288-96. [PubMed | Full Text | DOI]

26. Steele J, Shen J, Tsakos G, et al. The Interplay between socioeconomic inequalities and clinical oral health. J Dent Res. 2015 Jan;94(1):19-26. [PubMed | Full Text | DOI]

27. Bourgeois D, Hescot P, Doury J. Periodontal conditions in 35-44-yr-old adults in France, 1993. J Periodontal Res. 1997 Oct;32(7):570-4. [PubMed | Full Text | DOI]

28. Albandar JM, Rams TE. Global epidemiology of periodontal diseases: an overview. Periodontol 2000. 2002;29:7-10. [PubMed | Full Text | DOI]

29. Holtfreter B, Kocher T, Hoffmann T, et al. Prevalence of periodontal disease and treatment demands based on a German dental survey (DMS IV). J Clin Periodontol. 2010 Mar;37(3):211-9. [PubMed | Full Text | DOI]

30. Bonfim Mde L, Mattos FF, Ferreira e Ferreira E, et al. Social determinants of health and periodontal disease in Brazilian adults: a cross-sectional study. BMC Oral Health. 2013 May 20;13:13-22. [PubMed | Full Text | DOI] 